\title{
Mesocorticolimbic system abnormalities in chronic cluster headache patients: a neural signature?
}

\author{
Stefania Ferraro ${ }^{\mathrm{a}}$, Jean Paul Medina ${ }^{\mathrm{b}}$, Anna Nigri* b ${ }^{\mathrm{b}}$ Luca Giani ${ }^{\mathrm{c}}$, Greta Demichelis ${ }^{\mathrm{b}}$, Chiara Pinardi ${ }^{\mathrm{b}, \mathrm{d}}$, Maria Grazia \\ Bruzzone $^{\mathrm{b}}$, Alberto Proietti ${ }^{\mathrm{c}}$, Benjamin Becker ${ }^{\mathrm{a}}$, Luisa Chiapparini ${ }^{\mathrm{b}}$, Massimo Leone ${ }^{\mathrm{c}}$ \\ ${ }^{a}$ School of Life Science and Technology, MOE Key Laboratory for Neuroinformation, University of Electronic Science and Technology of China, Chengdu, China \\ ${ }^{b}$ Department of Neuroradiology, Fondazione IRCCS Neurologico 'Carlo Besta', Milan, Italy \\ ${ }^{c}$ Department of Neurology and Headache Centre, Fondazione IRCCS Neurologico 'Carlo Besta', Milan, Italy. \\ ${ }^{d}$ Medical Physics Unit, ASST Nord Milano, Sesto San Giovanni, Milan, Italy. \\ *Corresponding author: Anna Nigri, anna.nigri@istituto-besta.it
}

\begin{abstract}
BACKGROUND: Converging evidence suggests that anatomical and functional mesocorticolimbic abnormalities support the chronicization of pain disorders.

METHODS: We mapped structural and functional alterations of the mesocorticolimbic system in a sample of chronic cluster headache $(\mathrm{cCH})$ patients $(\mathrm{n}=28)$ in comparison to age and sex-matched healthy individuals $(\mathrm{n}=28)$ employing structural MRI and resting-state functional MRI (rs-fMRI).

RESULTS: Univariate logistic regression models showed that several of the examined structures/areas (i.e., the bilateral nucleus accumbens, ventral diencephalon, hippocampus, and frontal pole, and the right amygdala) differentiated cCH patients from healthy individuals ( $\mathrm{p}<0.05$, uncorrected). Specifically, all the significant structures/areas had increased volumes in cCH patients compared to healthy individuals. The examination of the groups suffering from left and right-sided cranial attacks showed a lateralization effect: ipsilateral to the pain ventral diencephalic regions and contralateral to the pain nucleus accumbens discriminated $\mathrm{cCH}$ patients from healthy individuals. The rs-fMRI data analyses showed that $\mathrm{cCH}$ patients compared to CTRL individuals present robust reduced functional connectivity in the right frontal pole-right amygdala pathway ( $<<0.05$, FDR-corrected).

CONCLUSION: Our results showed that $\mathrm{cCH}$ patients present anatomical and functional maladaptation of the mesocorticolimbic system, with functional data indicating a possible prefrontal areas' failure to modulate the mesolimbic structures. These results were opposite to what we hypothesized based on the previous literature on chronic pain conditions. Future studies should assess whether the observed mesocorticolimbic abnormalities are due to the neuroprotective effects of the assumed medications, or to the frequent comorbidity of $\mathrm{CH}$ with neuropsychiatric disorders or if they are a genuine neural signature of $\mathrm{CH}$ and/or $\mathrm{cCH}$ condition.
\end{abstract}

Keywords: Chronic cluster headache, Magnetic resonance imaging, Mesocorticolimbic system, Structural MRI, ROI-to-ROI rs-fMRI. 


\title{
Mesocorticolimbic system abnormalities in chronic cluster headache patients: a neural signature?
}

\author{
Stefania Ferraro ${ }^{\mathrm{a}}$, Jean Paul Medina ${ }^{\mathrm{b}}$, Anna Nigri* b ${ }^{\mathrm{b}}$, Luca Giani ${ }^{\mathrm{c}}$, Greta Demichelis ${ }^{\mathrm{b}}$, Chiara Pinardi ${ }^{\mathrm{b}, \mathrm{d}}$, Maria Grazia \\ Bruzzone $^{\mathrm{b}}$, Alberto Proietti ${ }^{\mathrm{c}}$, Benjamin Becker ${ }^{\mathrm{a}}$, Luisa Chiapparini ${ }^{\mathrm{b}}$, Massimo Leone ${ }^{\mathrm{c}}$ \\ ${ }^{a}$ School of Life Science and Technology, MOE Key Laboratory for Neuroinformation, University of Electronic Science and Technology of China, Chengdu, China \\ ${ }^{b}$ Department of Neuroradiology, Fondazione IRCCS Neurologico 'Carlo Besta', Milan, Italy \\ ${ }^{c}$ Department of Neurology and Headache Centre, Fondazione IRCCS Neurologico 'Carlo Besta', Milan, Italy. \\ ${ }^{d}$ Medical Physics Unit, ASST Nord Milano, Sesto San Giovanni, Milan, Italy. \\ *Corresponding author: Anna Nigri, anna.nigri@istituto-besta.it
}

\section{Introduction}

Cluster headache $(\mathrm{CH})$ is one of the most painful headaches with excruciating unilateral cranial pain, mainly around the orbital and temporal regions, and ipsilateral signs of cranial autonomic activity and/or sense of agitation or restlessness. The episodic form of the disorder is characterized by periods of multiple daily episodes lasting weeks or months followed by attackfree periods. If the symptomatic period does not remit within 12 months, the disorder is considered chronic $(\mathrm{cCH})$ (Olesen, 2018). Although the exact neuropathophysiology of $\mathrm{CH}$ is still to be clarified, convergent evidence from clinical, endocrinological, neuroimaging, and animal studies (May et al., 2018; Leone and Bussone, 2009), led to hypothesize a central role of the hypothalamus. In their seminal study, May et al. (1998) observed changes in metabolic activity during $\mathrm{CH}$ attacks in a region referred to the posterior hypothalamus (May et al., 1998), supporting the hypothesis that this structure plays a fundamental role in triggering attacks. However, the observation that deep brain stimulation (DBS) of this region and of the ventral tegmental area (VTA) modulate $\mathrm{CH}$ attacks within a broad temporal window (weeks or months)(Akram et al., 2016; Leone, 2006) re-framed the abnormal activity of the hypothalamus in a possible deranged functional network (Ferraro et al., 2018; Leone and Bussone, 2009). In our previous work, we showed that $\mathrm{cCH}$ patients present dysfunctional connectivity in a network seeded in the ipsilateral-to-the-pain (hereinafter defined as 'ipsilateral') posterior hypothalamus and comprising regions of the diencephalic-mesencephalic junction, specifically structures belonging to the midbrain dopaminergic systems, namely the VTA, substantia nigra, and subthalamic nucleus (Ferraro et al., 2018). These observations converge with the evidence of increased plasma levels of dopamine and other related neurotransmitters (D'Andrea et al., 2006, 2017) and with decreased responses of the growth hormone to apomorphine (Lepper et al., 2013) in $\mathrm{CH}$ patients, therefore supporting the involvement of the dopaminergic system in $\mathrm{CH}$ pathophysiology.

There is now ample evidence that chronic pain disorders are characterized by functional and anatomical abnormalities of the dopaminergic mesocorticolimbic system (Baliki et al., 2012; Vachon-Presseau et al., 2016), a broad network involved in motivational/reward behavior and comprising VTA, nucleus accumbens, amygdala, hippocampus, and prefrontal cortex (Serafini et al., 2020). In chronic pain, this circuit aberrantly responds to salient stimuli (Baliki et al., 2010) and presents altered dopamine transmission (Martikainen et al., 2015). This network seems to play a pivotal role in the transition from acute to chronic pain (Baliki et al., 2012; Vachon-Presseau et al., 2016) such that structural and functional connectivity in the prefrontal cortex-nucleus accumbens network and reduced amygdala and hippocampus volumes predict the development of chronic pain in individuals with subacute back pain. Moreover, when the pain becomes chronic, decreased grey matter volumes are observed in the nucleus accumbens (Baliki et al., 2012). Based on the conceptualization of $\mathrm{cCH}$ as a chronic pain disorder, we investigated the presence of structural and functional abnormalities of the mesocorticolimbic system in a relatively large sample of $\mathrm{cCH}$ patients $(\mathrm{n}=28)$ in comparison to matched healthy individuals $(n=28)$. To this aim, we employed structural magnetic resonance imaging (sMRI) and resting-state functional MRI (rs-fMRI). Specifically, we hypothesized that $\mathrm{cCH}$ patients are characterized by decreased volumes of the nucleus accumbens and by aberrant functional connectivity between the nucleus accumbens and prefrontal regions.

\section{Materials and Methods}

\subsection{Participants}

A consecutive sample of 28 patients (5 women; mean age \pm SD: $45 \pm 11.7$ years; age range: $28-70$ years) suffering from cCH underwent a cross-sectional MRI study (see table 1 and 2). Two expert neurologists (M.L. and A.P.) made the diagnosis according to the criteria of the International Classification of Headache Disorders (ICHD-3)(Headache Classification Committee of the International Headache Society, 2013). All 
patients were recruited among the $\mathrm{cCH}$ individuals hospitalized to treat the recurrent cluster headache attacks. Patients with a concurrent diagnosis of other primary or secondary headache disorders, cardiovascular diseases, diabetes mellitus, hypertension, or a history of psychiatric conditions were excluded from the study. Except for two, all patients took prophylactic treatment, with 13 patients treated with lithium. A sex and agematched sample of 28 healthy participants (CTRL), reporting no history of primary headache or chronic pain, was also recruited (mean age \pm SD: $45 \pm 10.1$ years). A subsample of $\mathrm{cCH}$ patients ( $n=19,2$ women; mean age \pm SD: $46 \pm 10.9$ years $)$ and age and sex-matched CTRL individuals ( $\mathrm{n}=18,2$ women; mean age \pm SD: $45 \pm 10.7$ years) also underwent rs-fMRI acquisitions (see table 3 ). The study was planned and conducted according to the Helsinki Declaration and approved by the Ethical Committee of the IRCCS Neurological Institute Carlo Besta. Each participant gave prior written informed consent.

\subsection{Descriptive statistics}

All statistical analyses were performed using R studio 3.5.1. To test for differences between $\mathrm{cCH}$ patients and CTRL group in terms of age, we used the Kruskall-Wallis test. Based on the predominant unilateral cranial symptoms, we investigated possible lateralization of the anatomical mesocorticolimbic alterations examining separately the group reporting left-sided attacks and the group reporting right-sided attacks (see Structural MRI data analyses paragraph). To verify the comparability of these two groups in terms of age, number of attacks per day, and years of chronicization, we employed Kruskall-Wallis tests.

\subsection{MRI assessments}

All participants were scanned with a $3 \mathrm{~T}$ scanner equipped with a 32-channels coil (Achieva TX, Philips Healthcare $\mathrm{BV}$, Best, NL). The MRI protocol included a volumetric high-resolution structural $3 \mathrm{D}$ T1-weighted (T1w) image $(\mathrm{TR}=9.86 \mathrm{~ms}, \mathrm{TE}=4.59 \mathrm{~ms}, \mathrm{FOV}=240 \times 240 \mathrm{~mm}$, voxel size $=1$ $\mathrm{mm}^{3}$, flip angle $=8^{\circ}, 185$ sagittal slices) and rs-fMRI images (GE-EPI volumes, TR=2800 ms, TE=30 ms, FOV=224x241, voxel size $=2.5 \mathrm{~mm}^{3}$, flip angle $=70^{\circ}, 50$ slices with $10 \%$ gap acquired in ascending order, 200 volumes). All the patients were scanned at least two hours after the last $\mathrm{CH}$ attack.

\subsection{Structural MRI data analyses}

sMRI results of this cohort of patients relative to abnormalities of the telencephalic and cerebellar cortical thickness were already published (Demichelis et al., 2021). For the current sMRI analyses, we employed the data from all the enrolled $\mathrm{cCH}$ and CTRL individuals. For each participant, we performed automated segmentation of the cerebral cortical areas and subcortical nuclei (FreeSurfer software v6.0 http://surfer.nmr.mgh.harvard.edu/) using as input the T1w image. Based on our a priori hypothesis, we focused on the following structures/areas of the mesocorticolimbic system: the ventral diencephalon, the hippocampus, the amygdala, the nucleus accumbens, and the medial prefrontal cortex (comprising the medial and lateral orbitofrontal cortex, the frontal pole, and the rostral anterior cingulate cortex). At the end of the automated pipeline (recon-all command), to remove pial-white boundary surfaces segmentation inaccuracies, visual inspection and manual correction of the segmentation were conducted by two expert operators (C.P. and G.D.) blind to the condition of the participants (cCH or CTRL). The volume of each structure/area of interest was extracted (from aseg and aparc files) and expressed as a percentage of total intracranial volume (TIV) to account for inter-subject cerebral volumes variability (Malone et al., 2015).

\section{Logistic regression analyses}

We assessed the statistical association between each extracted measure across the two groups of participants $(\mathrm{cCH}$ and CTRL participants) with respect to $\mathrm{CCH}$ diagnosis through univariate logistic regression models, using as covariates age and gender. Specifically, univariate logistic regression models were used to estimate how the volumes of the selected mesocorticolimbic structures affect the probability of belonging to the $\mathrm{cCH}$ group. Moreover, we evaluated the same statistical association separately for the left-lateralized attacks group $(n=12)$ and right-lateralized attacks group $(n=15)$. In this case, one patient with recurrent bilateral attacks was excluded from the analyses. We quantified the diagnostic discrimination of the univariate models using the area under a receiver operating characteristics curve (AUC). We used the maximum likelihood estimator to estimate the AUC, providing a score for each patient. To additionally control for possible effects of lithium, we assessed the statistical association between each extracted measure with respect to potential differences between lithiumtreated and non-lithium-treated patients at the time of scanning. Moreover, employing the Pearson correlation coefficient, we evaluated whether each investigated structure/area volume in $\mathrm{cCH}$ individuals correlated with the years of disease duration and with the number of headache attacks per day. Based on the specific a priori hypothesis, we considered results as significant for $\mathrm{p}<0.05$.

\section{5. rs-fMRI data analyses}

CONN toolbox (www.nitrc.org/projects/conn) was employed to analyze the rs-fMRI dataset. rs-fMRI scans underwent a series of standardized preprocessing steps comprising slicetiming correction, realignment, normalization to the MNI152 space, and spatial smoothing (6 mm FWHM Gaussian kernel). Preprocessed data were then denoised according to the CONN default pipeline. We then performed ROI-to-ROI functional connectivity (rs-FC) analysis. The ROIs were extracted from the Harvard-Oxford cortical and subcortical structural atlas, the default CONN atlas. In line with the morphological analyses, we selected the following ROIs: the hippocampus, the amygdala, the nucleus accumbens, and the medial prefrontal cortex (in this atlas identified as the medial frontal cortex, orbital frontal cortex, and frontal pole). The ventral diencephalon ROI was not present in this atlas; therefore, we extracted it from the atlas employed for the structural MRI analyses. In each subject, the mean average time-series of each ROI was computed, and 
for each possible pair of ROIs, a Fisher-transformed bivariate correlation coefficient was obtained. ROI-to-ROI rs-FC matrices were calculated. One sample t-tests were used to identify significant rs-FC among the investigated regions separately for CTRL and $\mathrm{cCH}$ individuals. Using age and gender as covariates, a one-way ANCOVA was employed to analyze betweengroup differences. Moreover, we investigated the correlation between the ROI-to-ROI rs-FC with the years of the chronicization of the disease and with the number of $\mathrm{CH}$ attacks per day in the $\mathrm{cCH}$ group. The results were considered significant for $\mathrm{p}<0.05$ FDR-corrected.

\section{Results}

\subsection{Descriptive statistics}

No significant differences emerged between $\mathrm{cCH}$ patients and CTRL individuals regarding age. No significant differences were observed between the group of patients with left-sided attacks and the group of right-sided attacks in terms of age, number of daily attacks, and disease duration.

\subsection{Structural MRI data results \\ Logistic regression analyses}

Univariate logistic regression models demonstrated that the bilateral nucleus accumbens, ventral diencephalon, hippocampus, and frontal pole, and the right amygdala significantly discriminated $\mathrm{cCH}$ patients from CTRL individuals (AUC range $=0.65-0.74$; see table 4 ). Moreover, the odds ratios (OR) of these significant models were positive, thus indicating that increasing the volume of the structure/area increases the likelihood of an individual to be categorized as a $\mathrm{cCH}$ patient. Remarkably, larger volumes were observed in the $\mathrm{cCH}$ group than in the CTRL group for all the significant structures/areas (table 4). All the models showed that age and gender did not significantly impact the discrimination accuracy; therefore, to avoid a reduction of degrees of freedom, we did not use these covariates in the subsequent morphological analyses. Logistic regression models also showed that the volumes of the right nucleus accumbens, the left ventral diencephalon, the right hippocampus, and the left frontal pole (AUC range=0.65-0.74) discriminated the left-sided attacks cCH group from the CTRL group. Similarly, the volumes of the left nucleus accumbens $(\mathrm{AUC}=0.79)$ and the right ventral diencephalon $(\mathrm{AUC}=0.68)$ for the rightsided attacks cCH group (see table 4 and figure 1). These results indicated that in both patients groups, the ipsilateral-to-the-pain (hereinafter defined as 'ipsilateral') ventral diencephalon and the contralateral-to-the-pain (hereinafter defined as 'contralateral') nucleus accumbens discriminated $\mathrm{cCH}$ patients from the CTRL individuals. Significantly, logistic regression models of all the investigated structures/areas did not discriminate between lithium-treated patients and non-lithium-treated patients (table 6). In cCH individuals, no significant correlations were observed between the volumes of the investigated structures and the years of the disease duration. A significant inverse correlation was observed between the volumes of the right frontal pole and the number of cluster headache attacks per day $(\mathrm{p}=0.022$; $r=-0.43)$.

\section{3. $r s-f M R I$ data results}

cCH patients compared the CTRL individual showed a robust reduced rs-FC in the right frontal pole-right amygdala pathway $(\mathrm{T}(34)=-3.74 ; \mathrm{p}=0.008$ FDR-corrected) (see 2). There were no significant correlations between the ROI-to-ROI rs-FC and the years of disease duration, and the number of headache attacks per day.

\section{Discussion}

Based on a strong a priori hypothesis, we mapped structural and rs-FC alterations of the mesocorticolimbic system in a relatively large sample of $\mathrm{cCH}$ patients compared with an age and sex-matched CTRL group. We report three main robust findings. First, employing logistic regression analyses on sMRI data, we demonstrated that $\mathrm{cCH}$ patients can be discriminated from CTRL individuals based on the volumes of several mesocorticolimbic structures/areas, specifically the bilateral ventral diencephalic region, the bilateral nucleus accumbens, the bilateral frontal pole, the bilateral hippocampus, and the right amygdala. Second, the separated investigations of the $\mathrm{cCH}$ groups reporting left-sided and right-sided cranial attacks shed light on the lateralization of these abnormalities: $\mathrm{cCH}$ patients were discriminated from CTRL individuals by the ipsilateral ventral diencephalic regions and by the contralateral nucleus accumbens. Remarkably, contrary to our hypothesis, all the mesocorticolimbic structures/areas showing significant diagnostic accuracy were larger in $\mathrm{cCH}$ individuals than in the CTRL group. Third, employing ROI-to-ROI rs-FC analyses, we showed that $\mathrm{cCH}$ patients present reduced rs-FC in the right frontal pole-right amygdala pathway.

There is now accumulating evidence that the mesocorticolimbic system plays a key role in motivated behavior and reward/aversive processing (Kringelbach and Berridge, 2015; Schultz, 2016). More recently, a central role in the transition from acute to chronic pain was also proposed (Baliki et al., 2012; Vachon-Presseau et al., 2016). This broad network originates from the dopaminergic inputs of the VTA targeting several subcortical and cortical brain regions involved in executive, affective and motivational behavior. Key areas of this circuit are also the nucleus accumbens and the medial prefrontal cortex, with a role also for the amygdala and the hippocampus (Navratilova and Porreca, 2014). Noxious stimuli were shown to reduce the activity of most of the mesolimbic dopamine neurons (value-coding neurons), but to increase the activity of a specific subpopulation of dopaminergic neurons (salience-coding neurons), leading to hypothesize the presence of a motivational salience signal rather than an intrinsic value signal of the input (Bromberg-Martin et al., 2010). In agreement, a separate dopaminergic circuit encoding for aversivepredicting stimuli has been identified from the ventral tegmental area to the ventral medial shell of the nucleus accumbens, and excitatory inputs from the lateral hypothalamus to the ventral nucleus accumbens were shown to mediate aversive-related behavior (de Jong et al., 2019). Moreover, neuronal changes in nucleus accumbens were linked to the impairment of motivation in chronic pain (Schwartz et al., 2014). Altogether, the 
above findings provided converging evidence that maladaptations of the dopaminergic mesocorticolimbic circuit may underlie abnormalities of the affective and motivational mechanisms in chronic pain, in agreement with the long-standing notion that chronic pain conditions are often in comorbidity with affective and emotional disorders (e.g., anxiety, depression) (Bushnell et al., 2013). Based on this background, a series of seminal studies, mainly conducted in back pain, has shown that chronic pain conditions are characterized by abnormal signaling of the end of acute pain in the nucleus accumbens during pain processing (Baliki et al., 2010), abnormalities of the striatal dopaminergic system (Martikainen et al., 2015), and temporal-dependent volume loss of the bilateral nucleus accumbens and insula cortex (Baliki et al., 2012). Moreover, smaller amygdala and hippocampal volumes and increased rsFC between the prefrontal cortex and nucleus accumbens were shown to be predictive of pain chronification (Baliki et al., 2012; Vachon-Presseau et al., 2016). This last finding, in particular, led to hypothesize the presence of an abnormal emotional signal disturbing the dopaminergic pathway from the ventral tegmental area, which in turn would modulate the thalamocortical network, which would result in an amplification of the nociceptive inputs (Vachon-Presseau et al., 2016). Notably, a recent study on trigeminal neuralgia, a chronic neuropathic pain, found evidence of bilateral volumetric decrease of the nucleus accumbens, ventral diencephalon, and hippocampus, supporting again the the notion of abnormal affective circuits in chronic pain conditions (Hayes et al., 2017).

$\mathrm{cCH}$ is a chronic pain condition, therefore the observed anatomical and functional abnormalities in the mesocorticolimbic system were not unexpected. However, instead of reduced volumes as observed in chronic pain, our results showed that cCH patients, compared to CTRL individuals, present increased volumes of most parts of the structures/areas of this system. Very remarkably, we observed that the ipsilateral ventral diencephalon volumes discriminate $\mathrm{cCH}$ patients from CTRL individuals, therefore indicating lateralization of the volumes abnormalities, very plausibly linked to the lateralization of the cranial pain. It is very important to note that the observed enlarged ipsilateral ventral diencephalon, a region comprising the hypothalamus, the basal forebrain, the sublenticular extended amygdala (SLEA), and the ventral tegmental area (Makris et al., 2008) is in agreement with the observations of increased volumes of the ipsilateral hypothalamus reported in the seminal study by May et al. (1999) and more recently observed by Arkink et al. (2017) and with the long-standing notion that the hypothalamic/ventral tegmental areas are involved in $\mathrm{CH}$ pathophysiology (Akram et al., 2016; Leone and Bussone, 2009; May et al., 2018). Interestingly, the nucleus accumbens presents a contralateral enlargement in $\mathrm{CCH}$ patients compared to CTRL participants. Although we have no clear explanation, this result again suggests a lateralization of the morphological abnormalities. It is plausible that in $\mathrm{cCH}$ patients, a potential reduced volume of ipsilateral nucleus accumbens, linked to a lateralized effect of this chronic pain condition, is compensated by possible neurotrophic effects of the assumed medications. In contrast, the non-affected contralateral nucleus accumbens might result in increased volumes.

Several and not mutually exclusive explanations may explain the divergent results in the context of the previous studies on chronic pain disorders. First, lithium, a mood-stabilizing medication with a therapeutic effect on $\mathrm{cCH}$ patients, is well known for its neurotrophic and neuroprotective effect (Manji et al., 2000). In bipolar disorders, the assumption of lithium is linked to increased volumes of the hippocampus (Yucel et al., 2008), thalamus (Hibar et al., 2016), frontal regions (Abramovic et al., 2016), and with clear effects on the nucleus accumbens shape (Vecchio et al., 2020). The use of lithium might explain the increased mesocorticolimbic volumes, and more specifically, the increased volumes of the contralateral nucleus accumbens, as discussed above. However, the observation that in our sample lithium was assumed, at the time of the MRI examination, in less than half of patients (13 out of 28) and that no significant differences emerged between the mesocorticolimbic volumes of the lithium-treated and non-lithium-treated patients render this possibility less probable. In this regard, we cannot exclude long-term effects of lithium interrupted in the past or that other employed medications in the investigated sample of $\mathrm{cCH}$ individuals might provide neuroprotective effects. Other possible explanations for the observed abnormalities include the comorbidity of CH condition with anxiety disorders (Robbins, 2013), linked to enlargement of the nucleus accumbens (Günther et al., 2018), and the use of the licit and illicit substance of abuse by CH individuals (Govare and Leroux, 2014). In this regard, animal studies have consistently shown increased dendritic spines in neurons of the nucleus accumbens in animals treated with morphine (Robinson and Kolb, 1999), cannabis (Kolb et al., 2006), nicotine (Brown and Kolb, 2001), and cocaine (Robinson et al., 2001). A third explanation is that the observed abnormalities of the mesocorticolimbic system could constitute the neural signature of the $\mathrm{cCH}$ or $\mathrm{CH}$ conditions.

Similarly to the structural results, we observed unexpected findings also for the rs-fMRI data: instead of increased rs-FC in $\mathrm{cCH}$ patients between the nucleus accumbens and the prefrontal regions as reported in chronic pain conditions (Baliki et al., 2012; Vachon-Presseau et al., 2016), we observed rs-FC reduction primarily in the right frontal pole-right amygdala pathway. Notably, inhibitory control of the prefrontal cortex over the nucleus accumbens dopamine release was shown to be modulated by the amygdala in animal models (Jackson and Moghaddam, 2001). Therefore, our results might indicate an imbalance of the frontal pole in control over the nucleus accumbens, possibly mediated by the activity of the amygdala. These results support the hypothesis of a failure of the frontal pole - amygdala functional pathway in modulating the mesolimbic activity in $\mathrm{cCH}$ patients (Piacentini et al., 2017).

Altogether, these unexpected findings underline the specificity of $\mathrm{cCH}$ in respect to other chronic pain conditions. In $\mathrm{CH}$, a chronic pattern may establish since the very beginning of the headache attacks; therefore, factors involved in the pathophysiology must differ from those known in chronic pain and in chronic migraine. This concept is further supported by the clinical experience of $\mathrm{cCH}$ cases with sudden and stable remission. Probably relevant to our results, at variance to other 
chronic pain disorders, is also the paroxysmal nature of $\mathrm{CH}$ attacks with sustained pain-free intervals between attacks, different from chronic pain with persistent-continuous pain perception all day long.

Although important for the possible implications, our results should be considered with great caution: we could not control the effects of the assumed medications and of the smoking habits, and we did not assess the impact of anxiety or depression, or other neuropsychiatric disorders in the investigated sample of $\mathrm{cCH}$ patients. Moreover, the fact that we did not compute the statistical power before conducting the experiment suggests evaluating the null findings carefully (Colegrave and Ruxton, 2003), especially the results from the sMRI analyses conducted in the subsamples of $\mathrm{cCH}$ individuals. Notably, rs-fMRI data were collected in a subsample of $\mathrm{cCH}$ patients $(\mathrm{n}=18)$, therefore to avoid a further reduction of the statistical power, we did not investigate the lateralization of the ROI-to-ROI rsFC abnormalities and the impact of the lithium treatment on the ROI-to-ROI rs-FC.

To conclude, we showed that $\mathrm{cCH}$ patients present anatomical and functional a maladaptation of the mesocorticolimbic system, however these results were opposite to what we hypothesized based on the previous literature on chronic pain conditions.

Future studies should assess whether the observed anatomical and functional abnormalities in $\mathrm{cCH}$ patients are linked to the neuroprotective effects of the assumed medications, or to the frequent comorbidity of $\mathrm{CH}$ with neuropsychiatric disorders or if they are a genuine neural signature (as neural bases or epiphenomenon) of $\mathrm{CH}$ and/or $\mathrm{cCH}$ disorder, promoting the disease itself or the development of the chronicization of the disease.

\section{Funding sources}

This work was supported by the Italian Ministry of Health, research grant RF-2016-02364909.

\section{Conflict of interest}

The Authors report non conflict of interest.

\section{References}

\section{References}

Abramovic, L., Boks, M.P., Vreeker, A., Bouter, D.C., Kruiper, C., Verkooijen, S., van Bergen, A.H., Ophoff, R.A., Kahn, R.S., van Haren, N.E., 2016. The association of antipsychotic medication and lithium with brain measures in patients with bipolar disorder. European Neuropsychopharmacology 26, $1741-1751$.

Akram, H., Miller, S., Lagrata, S., Hyam, J., Neurosurg, F., 2016. Ventral tegmental area deep brain stimulation for refractory chronic cluster headache 1-7doi:10.1093/aww233.

Arkink, E.B., Schmitz, N., Schoonman, G.G., Van Vliet, J.A., Haan, J., Van Buchem, M.A., Ferrari, M.D., Kruit, M.C., 2017. The anterior hypothalamus in cluster headache. Cephalalgia 37, 1039-1050. doi:10.1177/ 0333102416660550 .
Baliki, M.N., Geha, P.Y., Fields, H.L., Apkarian, A.V., 2010. Predicting value of pain and analgesia: nucleus accumbens response to noxious stimuli changes in the presence of chronic pain. Neuron 66, 149-160.

Baliki, M.N., Petre, B., Torbey, S., Herrmann, K.M., Huang, L., Schnitzer, T.J., Fields, H.L., Apkarian, A.V., 2012. Corticostriatal functional connectivity predicts transition to chronic back pain. Nature neuroscience 15, 1117.

Bromberg-Martin, E.S., Matsumoto, M., Hikosaka, O., 2010. Dopamine in motivational control: rewarding, aversive, and alerting. Neuron $68,815-$ 834.

Brown, R.W., Kolb, B., 2001. Nicotine sensitization increases dendritic length and spine density in the nucleus accumbens and cingulate cortex. Brain research 899, 94-100.

Bushnell, M.C., Čeko, M., Low, L.A., 2013. Cognitive and emotional control of pain and its disruption in chronic pain. Nature Reviews Neuroscience 14, 502-511.

Colegrave, N., Ruxton, G.D., 2003. Confidence intervals are a more useful complement to nonsignificant tests than are power calculations. Behavioral Ecology 14, 446-447.

D’Andrea, G., Granella, F., Perini, F., Farruggio, A., Leone, M., Bussone, G., 2006. Platelet levels of dopamine are increased in migraine and cluster headache. Headache: The Journal of Head and Face Pain 46, 585-591.

D'Andrea, G., Leone, M., Bussone, G., Fiore, P.D., Bolner, A., Aguggia, M., Saracco, M.G., Perini, F., Giordano, G., Gucciardi, A., Leon, A., 2017. Abnormal tyrosine metabolism in chronic cluster headache. Cephalalgia 37, 148-153. doi:10.1177/0333102416640502.

Demichelis, G., Pinardi, C., Giani, L., Medina, J.P., Gianeri, R., Bruzzone, M.G., Becker, B., Cecchini, A.P., Leone, M., Chiapparini, L., et al., 2021. Chronic cluster headache: a study of the telencephalic and cerebellar cortical thickness. medRxiv

Ferraro, S., Nigri, A., Bruzzone, M.G., Brivio, L., Proietti Cecchini, A., Verri, M., Chiapparini, L., Leone, M., 2018. Defective functional connectivity between posterior hypothalamus and regions of the diencephalicmesencephalic junction in chronic cluster headache. Cephalalgia 38, 19101918.

Govare, A., Leroux, E., 2014. Licit and illicit drug use in cluster headache. Current Pain and Headache Reports 18. doi:10.1007/s11916-014-0413-8.

Günther, V., Ihme, K., Kersting, A., Hoffmann, K.T., Lobsien, D., Suslow, T., 2018. Volumetric associations between amygdala, nucleus accumbens, and socially anxious tendencies in healthy women. Neuroscience 374, 25-32.

Hayes, D.J., Chen, D.Q., Zhong, J., Lin, A., Behan, B., Walker, M., Hodaie, M., 2017. Affective circuitry alterations in patients with trigeminal neuralgia. Frontiers in neuroanatomy 11,73 .

Hibar, D., Westlye, L.T., van Erp, T.G., Rasmussen, J., Leonardo, C.D., Faskowitz, J., Haukvik, U.K., Hartberg, C.B., Doan, N.T., Agartz, I., et al., 2016. Subcortical volumetric abnormalities in bipolar disorder. Molecular psychiatry $21,1710-1716$.

Headache Classification Committee of the International Headache Society, I.H.S., 2013. The international classification of headache disorders, (beta version). Cephalalgia 33, 629-808.

Jackson, M.E., Moghaddam, B., 2001. Amygdala regulation of nucleus accumbens dopamine output is governed by the prefrontal cortex. Journal of neuroscience 21, 676-681.

de Jong, J.W., Afjei, S.A., Dorocic, I.P., Peck, J.R., Liu, C., Kim, C.K., Tian, L., Deisseroth, K., Lammel, S., 2019. A neural circuit mechanism for encoding aversive stimuli in the mesolimbic dopamine system. Neuron 101, 133-151.

Kolb, B., Gorny, G., Limebeer, C.L., Parker, L.A., 2006. Chronic treatment with $\delta$-9-tetrahydrocannabinol alters the structure of neurons in the nucleus accumbens shell and medial prefrontal cortex of rats. Synapse 60, 429-436.

Kringelbach, M.L., Berridge, K.C., 2015. Motivation and pleasure in the brain. The psychology of desire, 129-145.

Leone, M., $2006 . \quad$ Deep brain stimulation in headache. The Lancet Neurology 5, 873-877. URL: http://www. sciencedirect.com/science/article/B6X3F-4KXFP40-S/ 2/6e57bc409ea71d0ac8ac80cacf88786c, doi:10.1016/ S1474-4422(06) 70575-0.

Leone, M., Bussone, G., 2009. Pathophysiology of trigeminal autonomic cephalalgias. The Lancet Neurology 8, 755-764. URL: http://dx.doi.org/10.1016/S1474-4422(09) 70133-4, doi:10.1016/S1474-4422(09)70133-4.

Lepper, A., Frese, A., Summ, O., Nofer, J.R., Evers, S., 2013. Hypothalamic dopaminergic stimulation in cluster headache. Cephalalgia 33, 1155-1159. 
Makris, N., Oscar-Berman, M., Jaffin, S.K., Hodge, S.M., Kennedy, D.N., Caviness, V.S., Marinkovic, K., Breiter, H.C., Gasic, G.P., Harris, G.J., 2008. Decreased volume of the brain reward system in alcoholism. Biological psychiatry 64, 192-202.

Malone, I.B., Leung, K.K., Clegg, S., Barnes, J., Whitwell, J.L., Ashburner, J., Fox, N.C., Ridgway, G.R., 2015. Accurate automatic estimation of total intracranial volume: a nuisance variable with less nuisance. Neuroimage 104, 366-372.

Manji, H.K., Moore, G.J., Chen, G., et al., 2000. Lithium up-regulates the cytoprotective protein bcl-2 in the cns in vivo: a role for neurotrophic and neuroprotective effects in manic depressive illness. Journal of Clinical Psychiatry $61,82-96$.

Martikainen, I.K., Nuechterlein, E.B., Pecina, M., Love, T.M., Cummiford, C.M., Green, C.R., Stohler, C.S., Zubieta, J.K., 2015. Chronic back pain is associated with alterations in dopamine neurotransmission in the ventral striatum. Journal of Neuroscience 35, 9957-9965.

May, A., Ashburner, J., Buchel, C., McGonigle, D.J., Friston, K.J., Frackowiak, R.S., Goadsby, P.J., 1999. Correlation between structural and functional changes in brain in an idiopathic headache syndrome. Nat Med 5, 836-838. URL: http://www.ncbi.nlm.nih.gov/pubmed/10395332\{\%\}5Cnhttp: //www.nature.com/nm/journal/v5/n7/pdf/nm0799\{_\}836.pdf, doi:10.1038/10561.

May, A., Bahra, A., Büchel, C., Frackowiak, R.S., Goadsby, P.J., 1998. Hypothalamic activation in cluster headache attacks. Lancet 352, 275-278. doi:10.1016/S0140-6736 (98) 02470-2.

May, A., Schwedt, T.J., Magis, D., Pozo-Rosich, P., Evers, S., Wang, S.J., 2018. Cluster headache. Nature Reviews Disease Primers 4, 1-17.

Navratilova, E., Porreca, F., 2014. Reward and motivation in pain and pain relief. Nature neuroscience 17, 1304-1312.

Olesen, J., 2018. International classification of headache disorders. The Lancet Neurology 17, 396-397.

Piacentini, S.H.M.J., Draghi, L., Cecchini, A.P., Leone, M., 2017. Personality disorders in cluster headache: a study using the millon clinical multiaxial inventory-iii. Neurological Sciences 38, 181-184.

Robbins, M.S., 2013. The psychiatric comorbidities of cluster headache. Current pain and headache reports 17, 313 .

Robinson, T.E., Gorny, G., Mitton, E., Kolb, B., 2001. Cocaine selfadministration alters the morphology of dendrites and dendritic spines in the nucleus accumbens and neocortex. Synapse 39, 257-266.

Robinson, T.E., Kolb, B., 1999. Morphine alters the structure of neurons in the nucleus accumbens and neocortex of rats. Synapse 33, 160-162.

Schultz, W., 2016. Dopamine reward prediction-error signalling: a twocomponent response. Nature reviews neuroscience 17, 183.

Schwartz, N., Temkin, P., Jurado, S., Lim, B.K., Heifets, B.D., Polepalli, J.S., Malenka, R.C., 2014. Decreased motivation during chronic pain requires long-term depression in the nucleus accumbens. Science 345, 535-542.

Serafini, R.A., Pryce, K.D., Zachariou, V., 2020. The mesolimbic dopamine system in chronic pain and associated affective comorbidities. Biological psychiatry $87,64-73$.

Vachon-Presseau, E., Tétreault, P., Petre, B., Huang, L., Berger, S.E., Torbey, S., Baria, A.T., Mansour, A.R., Hashmi, J.A., Griffith, J.W., et al., 2016. Corticolimbic anatomical characteristics predetermine risk for chronic pain. Brain 139, 1958-1970.

Vecchio, D., Piras, F., Piras, F., Banaj, N., Janiri, D., Simonetti, A., Sani, G., Spalletta, G., 2020. Lithium treatment impacts nucleus accumbens shape in bipolar disorder. NeuroImage: Clinical 25, 102167.

Yucel, K., Taylor, V.H., McKinnon, M.C., MacDonald, K., Alda, M., Young, L.T., MacQueen, G.M., 2008. Bilateral hippocampal volume increase in patients with bipolar disorder and short-term lithium treatment. Neuropsychopharmacology $33,361-367$. 
medRxiv preprint doi: https://doi.org/10.1101/2021.12.18.21268031; this version posted December 21, 2021. The copyright holder for this preprint (which was not certified by peer review) is the author/funder, who has granted medRxiv a license to display the preprint in

All rights reserved. No reuse allowed without permission.

Table 1: Demographic and clinical data of $\mathrm{cCH}$ and CTRL individuals submitted to the structural MRI acquisitions. Abbreviations: $\mathrm{cCH}=\mathrm{chronic}$ cluster headache group, $\mathrm{CTRL}=$ control group, $\mathrm{NA}=$ not applicable, ys = years, $\mathrm{M}=$ mean, $\mathrm{SD}=$ standard deviation, left-sided $=$ left-sided $\mathrm{CH}$ attacks, right-sided $=$ right-sided $\mathrm{CH}$ attacks.

\begin{tabular}{lllll}
\hline & $\mathrm{cCH}$ & $\mathrm{cCH}$ left-sided & cCH right-sided & $\mathrm{CTRL}$ \\
\hline \# participants & 28 & 12 & 15 & 28 \\
Age (ys; $\mathrm{M} \pm \mathrm{SD})$ & $45 \pm 11.7$ & $47 \pm 22.9$ & $48 \pm 3.6$ & $45 \pm 10$ \\
Males/Females & $23 / 5$ & $12 / 2$ & $12 / 3$ & $23 / 5$ \\
\# daily attacks $(\mathrm{M} \pm \mathrm{SD})$ & $5 \pm 2.3$ & $4 \pm 2.2$ & $5 \pm 2.5$ & $\mathrm{NA}$ \\
Disease duration $(\mathrm{ys} ; \mathrm{M} \pm \mathrm{SD})$ & $7 \pm 6.1$ & $6 \pm 6.4$ & $8 \pm 5.9$ & $\mathrm{NA}$ \\
\hline
\end{tabular}


Table 2: Current prophylactic treatment in $\mathrm{cCH}$ patient. Abbreviations: $\mathrm{M}=$ male, $\mathrm{F}=$ female, $\mathrm{L}=$ left, $\mathrm{R}=$ right, $\mathrm{BIL}=$ bilateral, $\mathrm{DD}=$ disease duration, $\mathrm{ys}=$ years.

\begin{tabular}{l|llllll}
\hline $\begin{array}{l}\text { Patient } \\
\text { ID }\end{array}$ & Gender & $\begin{array}{l}\text { Age } \\
\text { (ys) }\end{array}$ & $\begin{array}{l}\text { Side of } \\
\text { attack }\end{array}$ & $\begin{array}{l}\text { DD } \\
(\mathrm{ys})\end{array}$ & $\begin{array}{l}\text { \# daily } \\
\text { attacks }\end{array}$ & Prophylaxis \\
\hline 1 & $\mathrm{M}$ & $31-40$ & $\mathrm{~L}$ & 10 & 5 & Verapamil, Valproate \\
2 & $\mathrm{M}$ & $31-40$ & $\mathrm{~L}$ & 3 & 2 & Verapamil, Valproate \\
3 & $\mathrm{M}$ & $61-70$ & $\mathrm{~L}$ & 6 & 3 & Carbolithium, Pizotifen \\
4 & $\mathrm{M}$ & $61-70$ & $\mathrm{~L}$ & 0.33 & 2 & Verapamil, Carbolithium, Dexamethasone \\
5 & $\mathrm{M}$ & $31-40$ & $\mathrm{~L}$ & 2 & 8 & Carbolithium \\
6 & $\mathrm{M}$ & $41-50$ & $\mathrm{~L}$ & 25 & 8 & Verapamil \\
7 & $\mathrm{M}$ & $61-70$ & $\mathrm{~L}$ & 5 & 2 & Verapamil, Carbolithium \\
8 & $\mathrm{~F}$ & $31-40$ & $\mathrm{~L}$ & 4 & 2 & Valproate, Verapamil, Carbolithium \\
9 & $\mathrm{M}$ & $41-50$ & $\mathrm{~L}$ & 4 & 4 & Verapamil \\
10 & $\mathrm{M}$ & $41-50$ & $\mathrm{~L}$ & 3 & 5 & Verapamil \\
11 & $\mathrm{~F}$ & $51-60$ & $\mathrm{~L}$ & 1 & 2 & Verapamil \\
12 & $\mathrm{M}$ & $41-50$ & $\mathrm{~L}$ & 5 & 2 & Carbolithium \\
13 & $\mathrm{M}$ & $21-30$ & $\mathrm{R}$ & 7 & 7 & Verapamil, Valproate \\
14 & $\mathrm{M}$ & $31-40$ & $\mathrm{R}$ & 3 & 8 & Verapamil, Carbolithium \\
15 & $\mathrm{M}$ & $41-50$ & $\mathrm{R}$ & 2 & 4 & Verapamil, Dexamethasone, Valproate \\
16 & $\mathrm{M}$ & $61-70$ & $\mathrm{R}$ & 0.5 & 2 & Verapamil, Carbolithium \\
17 & $\mathrm{M}$ & $41-50$ & $\mathrm{R}$ & 10 & 5 & None \\
18 & $\mathrm{~F}$ & $51-60$ & $\mathrm{R}$ & 1 & 2 & Carbolithium, Dexamethasone \\
19 & $\mathrm{~F}$ & $21-30$ & $\mathrm{R}$ & 2 & 2 & None \\
20 & $\mathrm{M}$ & $31-40$ & $\mathrm{R}$ & 9 & 6 & Carbolithium \\
21 & $\mathrm{M}$ & $31-40$ & $\mathrm{R}$ & 18 & 4 & Valproate \\
22 & $\mathrm{M}$ & $41-50$ & $\mathrm{R}$ & 15 & 8 & Verapamil, Carbolithium \\
23 & $\mathrm{M}$ & $41-50$ & $\mathrm{R}$ & 9 & 3 & Verapamil, Carbolithium \\
24 & $\mathrm{~F}$ & $41-50$ & $\mathrm{R}$ & 4 & 4 & Duloxetine, Amitripyline \\
25 & $\mathrm{M}$ & $41-50$ & $\mathrm{R}$ & 10 & 5 & Dexamethasone, Topiramate \\
26 & $\mathrm{M}$ & $41-50$ & $\mathrm{R}$ & 8 & 4 & Dexamethasone, Verapamil, Carbolithium \\
27 & $\mathrm{M}$ & $51-60$ & $\mathrm{R}$ & 20 & 2 & Dexamethasone \\
28 & $\mathrm{M}$ & $31-40$ & $\mathrm{BIL}$ & 1 & 3 & Dexamethasone \\
\hline & & & & & & \\
\end{tabular}


medRxiv preprint doi: https://doi.org/10.1101/2021.12.18.21268031; this version posted December 21, 2021. The copyright holder for this preprint (which was not certified by peer review) is the author/funder, who has granted medRxiv a license to display the preprint in

All rights reserved. No reuse allowed without permission.

Table 3: Demographic and clinical data of the subsamples of $\mathrm{cCH}$ and $\mathrm{CTRL}$ individuals submitted to the rs-fMRI acquisitions. Abbreviations: $\mathrm{cCH}=\mathrm{chronic}$ cluster headache group, $\mathrm{CTRL}=$ control group, $\mathrm{NA}=$ not applicable, ys $=$ years, $\mathrm{M}=$ mean, $\mathrm{SD}=$ standard deviation, left-sided $=$ left-sided $\mathrm{CH}$ attacks, right-sided $=$ right-sided $\mathrm{CH}$ attacks.

\begin{tabular}{lllll}
\hline & $\mathrm{cCH}$ & $\mathrm{cCH}$ left-sided & $\mathrm{cCH}$ right-sided & CTRL \\
\hline \# participants & 19 & 8 & 11 & 18 \\
Age $(\mathrm{ys} ; \mathrm{M} \pm \mathrm{SD})$ & $46 \pm 10.9$ & $49 \pm 12.9$ & $44 \pm 9.4$ & $44 \pm 9.7$ \\
Males/Females & $16 / 3$ & $7 / 1$ & $9 / 2$ & $16 / 2$ \\
\# daily attacks $(\mathrm{M} \pm \mathrm{SD})$ & $5 \pm 2.2$ & $5 \pm 2.4$ & $5 \pm 2.1$ & $\mathrm{NA}$ \\
Disease duration $(\mathrm{ys} ; \mathrm{M} \pm \mathrm{SD})$ & $8 \pm 6.7$ & $7 \pm 7.7$ & $9 \pm 6.1$ & $\mathrm{NA}$ \\
\hline
\end{tabular}


Table 4: Logistic regression models of the volumes (expressed as a percentage of the total intracranial volume) of the structures/areas of the mesocorticolimbic system estimating the probability of the cCH condition (Overall - $28 \mathrm{cCH}$ individuals), of the left-sided attacks cCH condition (Left-sided attacks $-12 \mathrm{cCH}$ patients), and of the right-sided attacks $\mathrm{cCH}$ condition (Right-sided attacks -15 cCH patients) in respect to $\mathrm{CTRL}$ condition (28 healthy individuals). Abbreviations: OR: Odds Ratio, $\mathrm{CI}=$ confidence interval, $\mathrm{AUC}=$ area under the curve, $\mathrm{R}=$ right, $\mathrm{L}=$ left, $\mathrm{cCH}=\mathrm{chronic}$ cluster headache condition; $\mathrm{CTRL}=$ control condition

\begin{tabular}{|c|c|c|c|c|c|c|c|c|c|c|c|c|c|}
\hline & Overall & & & & & Left-s & ided attacks & & & Right & sided attack & & \\
\hline Marker & $\mathbf{O R} \sim$ & $95 \% \mathrm{CI}$ & P-value & $\mathbf{A U C}$ & $95 \% \mathrm{CI}$ & $\mathbf{O R} \sim$ & $95 \% \mathrm{CI}$ & P-value & $\mathbf{A U C}$ & $\mathbf{O R} \sim$ & $95 \% \mathrm{CI}$ & P-value & $\overline{\mathbf{A U C}}$ \\
\hline L nucleus accumbens & 4.34 & $1.63-14.54$ & 0.008 & 0.73 & $0.59-0.87$ & 3.34 & $1.07-12.77$ & 0.05 & 0.66 & 6.49 & $1.82-34.25$ & 0.01 & 0.79 \\
\hline $\mathrm{R}$ nucleus accumbens & 3.44 & $1.18-11.78$ & 0.033 & 0.65 & $0.50-0.80$ & 458 & $1.24-20.72$ & 0.03 & 0.67 & 3.81 & $0.92-19.83$ & 0.08 & 0.67 \\
\hline L ventral diencephalon & 1.38 & $1.07-1.89$ & 0.024 & 0.67 & $0.53-0.81$ & 164 & $1.13-2.59$ & 0.02 & 0.73 & 1.31 & $0.98-1.93$ & 0.11 & 0.63 \\
\hline$R$ ventral diencephalon & 1.36 & $1.05-1.90$ & 0.040 & 0.65 & $0.50-0.79$ & 1.36 & $0.99-2.11$ & 0.10 & 0.63 & 1.46 & $1.05-2.18$ & 0.04 & 0.68 \\
\hline L hippocampus & 1.23 & $1.01-1.57$ & 0.065 & 0.66 & $0.51-0.80$ & 1.23 & $0.96-1.64$ & 0.11 & 0.66 & 1.25 & $0.98-1.73$ & 0.12 & 0.66 \\
\hline $\mathrm{R}$ hippocampus & 1.31 & $1.06-1.72$ & 0.025 & 0.69 & $0.55-0.83$ & 1.50 & $1.10-2.08$ & 0.02 & 0.74 & 1.23 & $0.97-1.65$ & 0.12 & 0.65 \\
\hline L amygdala & 1.35 & $0.83-2.31$ & 0.248 & 0.57 & $0.42-0.73$ & 1.73 & $0.87-3.91$ & 0.14 & 0.63 & 1.07 & $0.55-2.05$ & 0.84 & 0.51 \\
\hline $\mathrm{R}$ amygdala & 1.65 & $0.99-2.99$ & 0.068 & 0.64 & $0.49-0.79$ & 2.07 & $1.00-5.02$ & 0.07 & 0.67 & 1.58 & $0.86-3.17$ & 0.16 & 0.63 \\
\hline $\mathrm{L}$ frontal pole & 1.76 & $1.04-3.21$ & 0.047 & 0.65 & $0.50-0.79$ & 2.12 & $1.11-4.762$ & 0.04 & 0.69 & 1.38 & $0.70-2.86$ & 0.36 & 0.59 \\
\hline $\mathrm{R}$ frontal pole & 1.81 & $1.06-3.32$ & 0.039 & 0.70 & $0.50-0.84$ & 164 & $0.89-3.26$ & 0.13 & 0.70 & 1,76 & $0.96-3.58$ & 0.08 & 0.71 \\
\hline L lateralorbitofrontal & 1.02 & $0.93-1.14$ & 0.623 & 0.47 & $0.32-0.63$ & 1.09 & $0.97-1.26$ & 0.17 & 0.43 & 0.95 & $0.80-1.10$ & 0.47 & 0.59 \\
\hline $\mathrm{R}$ lateralorbitofrontal & 0.98 & $0.88-1.10$ & 0.755 & 0.42 & $0.27-0.57$ & 1.05 & $0.92-1.20$ & 0.46 & 0.51 & 0.85 & $0.67-1.01$ & 0.10 & 0.67 \\
\hline L medialorbitofrontal & 1.06 & $0.94-1.22$ & 0.369 & 0.54 & $0.38-0.69$ & 1.06 & $0.91-1.26$ & 0.44 & 0.49 & 1.06 & $0.90-1.27$ & 0.50 & 0.55 \\
\hline R medialorbitofrontal & 1.02 & $0.88-1.19$ & 0.767 & 0.49 & $0.34-0.65$ & 1.13 & 0.94-1.39 & 0.21 & 0.57 & 0.96 & $0.77-1.18$ & 0.67 & 0.53 \\
\hline $\mathrm{L}$ rostralanteriorcingulate & 0.84 & $0.65-1.05$ & 0.141 & 0.37 & $0.22-0.53$ & 0.90 & $0.65-1.22$ & 0.52 & 0.58 & 0.78 & $0.55-1.05$ & 0.12 & 0.65 \\
\hline $\mathrm{R}$ rostralanteriorcingulate & 0.89 & $0.70-1.11$ & 0.331 & 0.39 & $0.24-0.54$ & 0.96 & $0.70-1.23$ & 0.74 & 0.62 & 0.74 & $0.51-1.03$ & 0.09 & 0.63 \\
\hline
\end{tabular}


Table 5: Mean and standard deviations of the volumes of the investigated structures/areas (expressed as \% of the total intracranial volume - TIV) of the mesocorticolimbic system: Abbreviations: $c$ CH $=$ chronic cluster headache patients, $\mathrm{CTRL}=$ control individuals, $\mathrm{M}=$ mean, $\mathrm{SD}=$ standard deviation, $\mathrm{L}=$ left, $\mathrm{R}=$ right.

\begin{tabular}{l|llll}
\hline Marker & cCH & \multicolumn{3}{l}{ CTRL } \\
\hline & M & SD & M & SD \\
\hline L nucleus accumbens & 0.028 & 0.007 & 0.023 & 0.005 \\
R nucleus accumbens & 0.033 & 0.006 & 0.030 & 0.004 \\
L ventral diencephalon & 0.283 & 0.028 & 0.268 & 0.018 \\
R ventral diencephalon & 0.276 & 0.030 & 0.261 & 0.014 \\
L hippocampus & 0.273 & 0.031 & 0.258 & 0.024 \\
R hippocampus & 0.282 & 0.031 & 0.263 & 0.023 \\
L amygdala & 0.101 & 0.013 & 0.097 & 0.008 \\
R amygdala & 0.116 & 0.012 & 0.110 & 0.009 \\
\hline L frontal pole & 0.061 & 0.011 & 0.055 & 0.010 \\
R frontal pole & 0.071 & 0.009 & 0.065 & 0.011 \\
L lateralorbitofrontal & 0.456 & 0.066 & 0.449 & 0.043 \\
R lateralorbitofrontal & 0.445 & 0.057 & 0.450 & 0.041 \\
L medialorbitofrontal & 0.309 & 0.046 & 0.299 & 0.039 \\
R medialorbitofrontal & 0.319 & 0.041 & 0.316 & 0.031 \\
L rostralanteriorcingulate & 0.116 & 0.028 & 0.122 & 0.021 \\
R rostralanteriorcingulate & 0.141 & 0.026 & 0.151 & 0.021 \\
\hline
\end{tabular}




\begin{tabular}{cccccc}
\hline Marker & OR & 95\% CI & P-value & AUC & 95\% CI \\
\hline L nucleus accumbens & 1.31 & $0.47-3.94$ & 0.61 & 0.55 & $0.32-0.79$ \\
R nucleus accumbens & 1.13 & $0.32-4.08$ & 0.85 & 0.52 & $0.30-0.75$ \\
L ventral diencephalon & 1.00 & $0.75-1.33$ & 0.99 & 0.50 & $0.28-0.73$ \\
R ventral diencephalon & 1.10 & $0.85-1.48$ & 0.46 & 0.58 & $0.36-0.80$ \\
L hippocampus & 0.88 & $0.65-1.13$ & 0.36 & 0.43 & $0.21-0.65$ \\
R hippocampus & 0.82 & $0.57-1.06$ & 0.18 & 0.63 & $0.41-0.84$ \\
L amygdala & 0.75 & $0.38-1.35$ & 0.36 & 0.46 & $0.23-0.70$ \\
R amygdala & 0.62 & $0.28-1.19$ & 0.18 & 0.62 & $0.39-0.85$ \\
L frontal pole & 0.43 & $0.14-0.96$ & 0.07 & 0.68 & $0.47-0.88$ \\
R frontal pole & 0.51 & $0.17-1.24$ & 0.16 & 0.63 & $0.41-0.85$ \\
L lateralorbitofrontal & 0.95 & $0.81-1.07$ & 0.45 & 0.549 & $0.33-0.77$ \\
R lateralorbitofrontal & 0.89 & $0.71-1.04$ & 0.24 & 0.69 & $0.48-0.89$ \\
L medialorbitofrontal & 0.95 & $0.78-1.12$ & 0.54 & 0.57 & $0.34-0.81$ \\
R medialorbitofrontal & 1.01 & $0.83-1.22$ & 0.95 & 0.50 & $0.27-0.73$ \\
L rostralanteriorcingulate & 1.27 & $0.94-1.80$ & 0.14 & 0.62 & $0.39-0.85$ \\
R rostralanteriorcingulate & 0.92 & $0.65-1.22$ & 0.58 & 0.48 & $0.25-0.70$ \\
\hline
\end{tabular}


medRxiv preprint doi: https://doi.org/10.1101/2021.12.18.21268031; this version posted December 21, 2021. The copyright holder for this preprint (which was not certified by peer review) is the author/funder, who has granted medRxiv a license to display the preprint in perpetuity.

All rights reserved. No reuse allowed without permission.

Figure 1: Structural MRI data results: Boxplots of the volumes (expressed as a percentage of the total intracranial volume) of the mesocorticolimbic structures/areas in chronic cluster headache ( $\mathrm{cCH}$ ) and control participants (CTRL) and the respective receiver operating characteristic (ROC) curves for the diagnostic accuracy of the classifiers (univariate logistic regression models). ${ }^{*}$ Structures/areas significantly discriminating $\mathrm{cCH}$ patients from $\mathrm{CTRL}$ individuals. Abbreviations: $\mathrm{cCH}=$ chronic cluster headache patients, $\mathrm{CTRL}=$ control individuals.
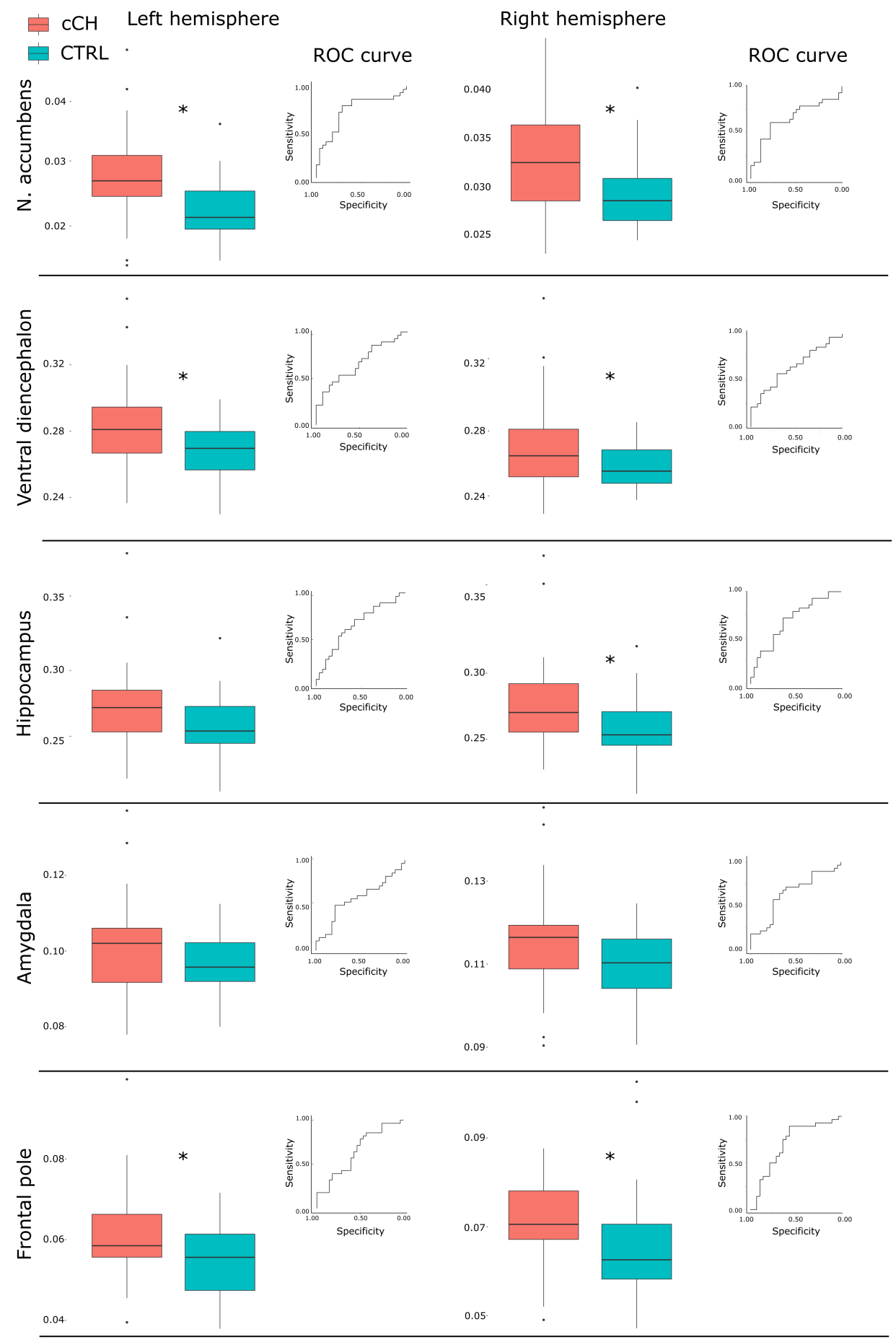
medRxiv preprint doi: https://doi.org/10.1101/2021.12.18.21268031; this version posted December 21, 2021. The copyright holder for this preprint (which was not certified by peer review) is the author/funder, who has granted medRxiv a license to display the preprint in perpetuity.

All rights reserved. No reuse allowed without permission.

Figure 2: ROI-to-ROI resting-state functional connectivity (rs-FC). Connectome ring representations of the significant ROI-to-ROI rs-FC of the investigated structures/areas of the mesocorticolimbic system for $\mathrm{cCH}$ patients, CTRL individuals and representation of the reduction of the rs-FC in the functional pathway right frontal-pole-right amygdala in $\mathrm{cCH}$ patients compared to CTRL individuals $(\mathrm{p}<0.05$ FDR-corrected). The color bars represent $\mathrm{T}$ values. Abbreviations: $\mathrm{cCH}=$ chronic cluster headache patients, $\mathrm{CTRL}=$ control individuals.
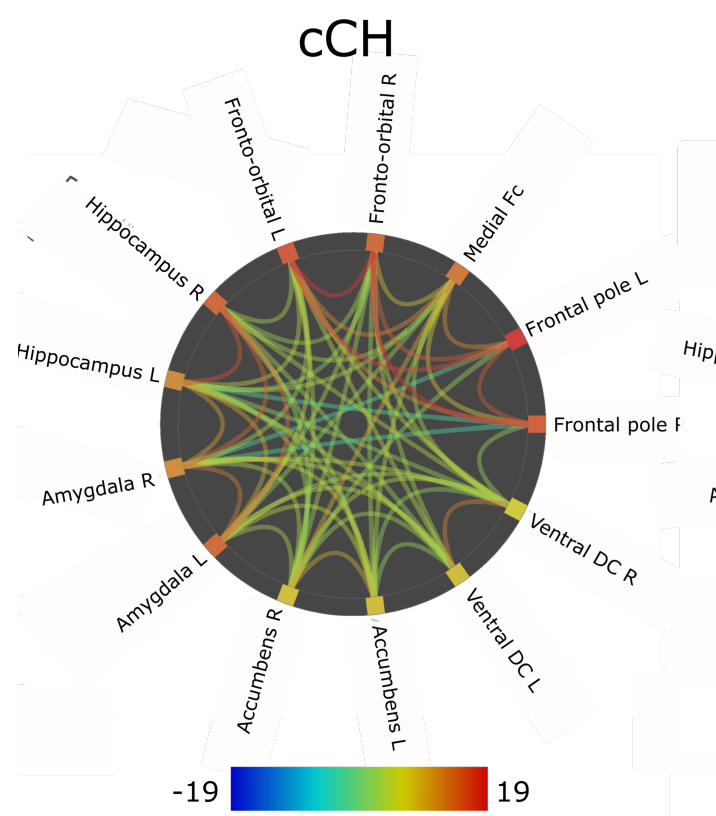

\section{CTRL}

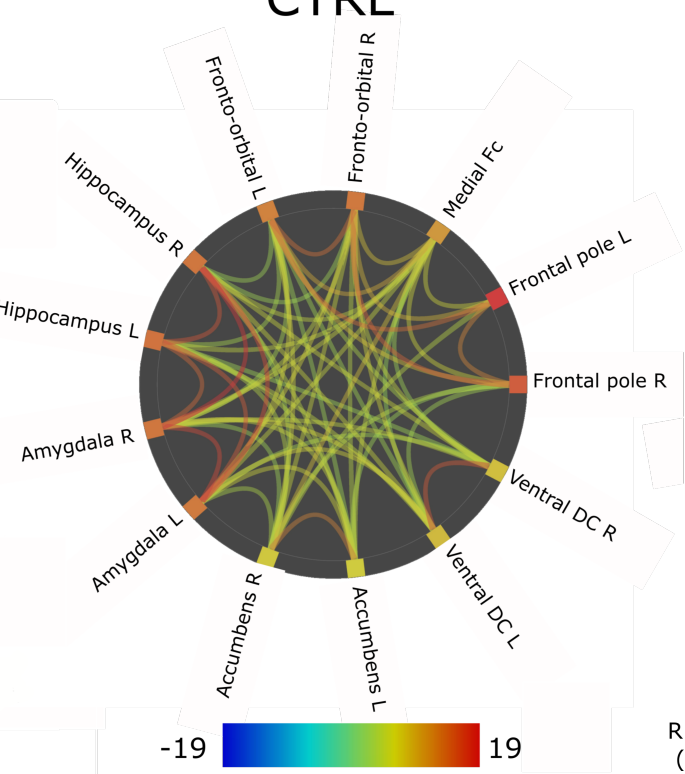

CCH vS CTRL

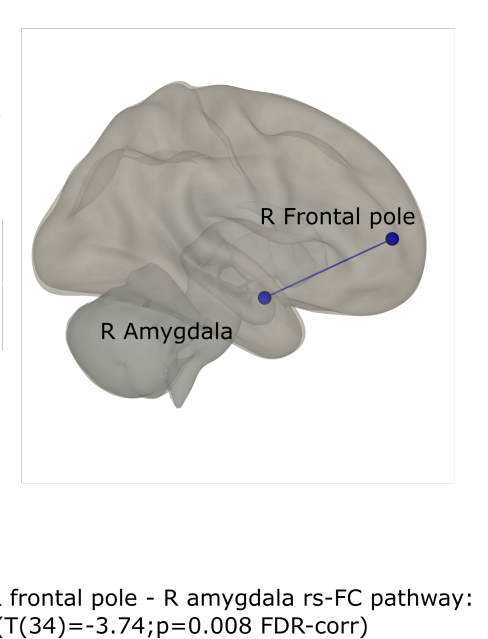

